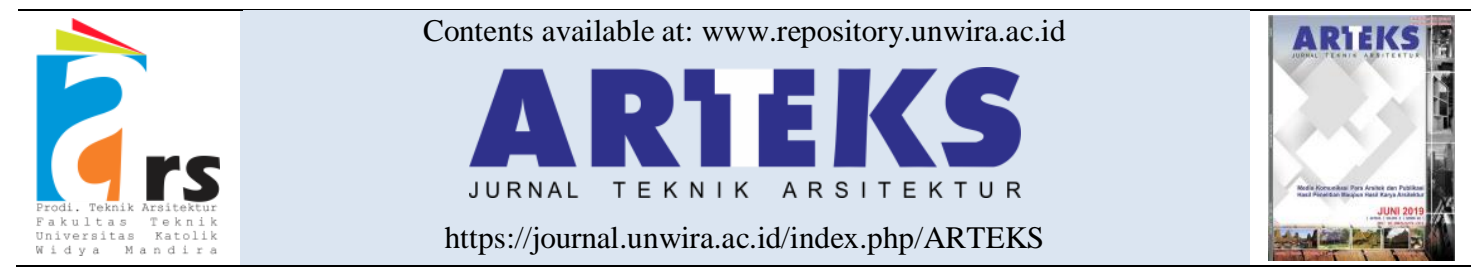

Research paper

doi: 10.30822/arteks.v5i2.391

\title{
Perancangan coconut center dengan pendekatan biomimetika di Tembilahan
}

\author{
Kemas Roqim Azyan, Yohannes Firzal*(D), Mira Dharma Susilawaty \\ Jurusan Arsitektur, Fakultas Teknik, Universitas Riau \\ Kampus Binawidya, Jl. HR. Soebrantas KM. 12,5 Pekanbaru, Indonesia
}

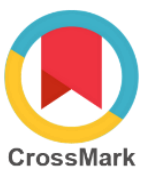

\begin{tabular}{l}
\hline ARTICLE INFO \\
\hline Article history: \\
Received February 13, 2020 \\
Received in revised form March 13, \\
2020 \\
Accepted April 18, 2020 \\
Available online August 01, 2020
\end{tabular}

\section{Keywords: \\ Architectural design \\ Biomimetic concept \\ Coconut center design \\ Tembilahan}

*Corresponding author: Yohannes Firzal Jurusan Arsitektur, Fakultas Teknik, Universitas Riau, Indonesia

Email: yfirza@eng.unri.ac.id

ORCID: https://orcid.org/0000-0001-5990-

$861 \mathrm{X}$ \begin{abstract} Coconut center design with biomimetic approach in Tembilahan

Tembilahan is known as the country of the coconut expanse of the world who has the industry made from coconut, both from shell, stem and even from coconut fiber. The potential of the industry made from coconut in Indragiri Hilir has not received a positive response from the society because of the intense competition with the production of other raw materials., whereas coconut is one of the highest potentials that can be utilized to improve the regional economy. To support the development of the coconut industry, a coconut center is needed to accommodate a variety of activities related to coconuts such as handicraft centers and coconut development. By using a primary method in the form of a survey, as well as various sources of literature as a secondary method. In the design of the coconut center architecture, this biomimetic Architecture theme approach will be used which uses nature as a model and reference in design ideas; it can strengthen the natural aspects of the design object that refers to the function of crafts, research, production, education, and recreation.
\end{abstract}

\section{Pendahuluan}

Provinsi Riau merupakan wilayah perkebunan kelapa terbesar di Indonesia, dan daerah yang paling produktif, berada di area lahan gambut di Kabupaten Indragiri Hilir dengan luas lahan 429.110 hektar, mulai dari ujung Utara di Kecamatan Pulau Burung hingga ke Selatan di Kecamatan Reteh (Agustin, Firzal, and Aldy 2018). Kebun kelapa yang luas, membuat Indragiri Hilir mendapat julukan Negeri Hamparan Kelapa Dunia (Vaulina 2019). Kelapa memang menjadi tumpuan mata pencaharian pokok masyarakat Indragiri Hilir (Hadi 2017). Kebun-kebun kelapa diolah, mulai dari mengambil buah bulatnya hingga menjadi pelbagai produk turunan (Kementerian Perdagangan Republik Indonesia 2017).
Kelapa memiliki nilai komersial tinggi, mulai dari batang, buah, sabut, tempurung, sampai air kelapa. Produk-produk dari buah kelapa banyak diminati karena memiliki nilai ekonomi tinggi. Antara lain CCO (Coconut Crude Oil), VCO (Virgin Coconut Oil), AC (Activated Carbon), CF (Coconut Fiber), CCL (Coconut Charcoal), serta oleokimia untuk menghasilkan asam lemak, metal ester, fattyalkohol, fatty amine, fatty nitrogen, dan glycerol (Bhikuning 2013). Sementara itu, daun, sabut, dan batang kelapa memiliki prospek bagus sebagai bahan baku industri untuk menghasilkan perlengkapan rumah tangga (furniture) seperti keset, sapu, spring bed, matras dan masih banyak lagi (Indahyani 2011).

Berdasarkan fenomena potensi kelapa di Inddragiri Hilir, maka perancangan coconut center dapat mewadahi pelbagai macam kegiatan 
yaitu kerajinan kelapa yang dapat menjadi wadah bagi masyarakat untuk membuat pelbagai macam kerajinan berbahan baku kelapa, sebagai pusat penelitian kelapa, kegiatan edukasi, museum, retail, juga rekreasi bagi masyarakat, dan ekonomi. Pusat kerajinan membuat peningkatan ekonomi kreatif bagi pelaku usaha perdagangan kreatif (Fitriana 2014). Dengan menghadirkan coconut center di Tembilahan dapat meningkatkan dan berdampak bagi perekonomian juga parawisata, serta sebagai wadah untuk peningkatan potensi kerajinan kelapa. Tema arsitektur biomimetika diaplikasikan ke perancangan coconut center di Tembilahan bertujuan untuk memaksimalkan fungsi, mencapai efisiensi energi, dan meningkatkan kualitas objek dan aktivitas pengguna melalui penerapan kriteria-kriteria biologis serta meminimalisir dampak negatif yang dihasilkan oleh objek rancangan (Eman and Rogi 2013). Dengan pendekatan tema arsitektur biomimetika pada dasarnya menggunakan alam sebagai model dan acuan dalam ide-ide perancangan (Schouten, Sangkertadi, and Siregar 2015; Baumeister 2012). Perancangan coconut center dengan pendekatan biomimetika di Tembilahan yang memiliki tantangan masalah sebagai berikut:

1. Bagaimana menyusun kebutuhan dan fungsi ruang yang efektif dengan kegiatan yang akan diwadahi di coconut center di Tembilahan?

2. Bagaimana menerapkan pendekatan biomimetika pada coconut center di Tembilahan?

3. Bagaimana menerapkan konsep perancangan pada coconut center dengan pendekatan biomimetika di Tembilahan?

\section{Metode penelitian}

\section{Paradigma perancangan}

Perancangan coconut center dengan pendekatan biomimetika di Tembilahan ini adalah tanggapan dari tidak adanya wadah bagi masyarakat Indragiri Hilir untuk dapat memaksimalkan kelapa yang merupakan komoditi terbaik daerah, dan juga tidak adanya sebuah bangunan yang dapat mewadahi pelbagai macam kegiatan berkaitan dengan kelapa.

Pendekatan arsitektur biomimetika memiliki kesesuaian untuk diterapkan pada bangunan coconut center yaitu bagaimana menciptakan hubungan antara buah kelapa yang berasal dari alam dengan arsitektur.

Strategi perancangan

Penyusunan strategi perancangan coconut center di Tembilahan dengan pendekatan biomimetika menggunakan beberapa strategi dalam pengambilan data yaitu dimulai dari studi literatur, mencari pengertian dan sifat-sifat pada pohon kelapa, analisa fungsi, analisa site, program ruang, penzoningan, konsep, bentukan massa, sistem bangunan, denah, sirkulasi, fasad, lansekap, hingga mendapatkan hasil desain (Lihat gambar 1).

\section{Metode pengumpulan data}

Pengumpulan dan pengolahan data yang di analisis dalam rancangan ini ada dua macam yaitu data primer yang didapatkan melalui survey lapangan (observasi) dokumentasi, dan data sekunder yang didapatkan melalui skripsi, tesis, atau disertasi, jurnal, buku, dan media.

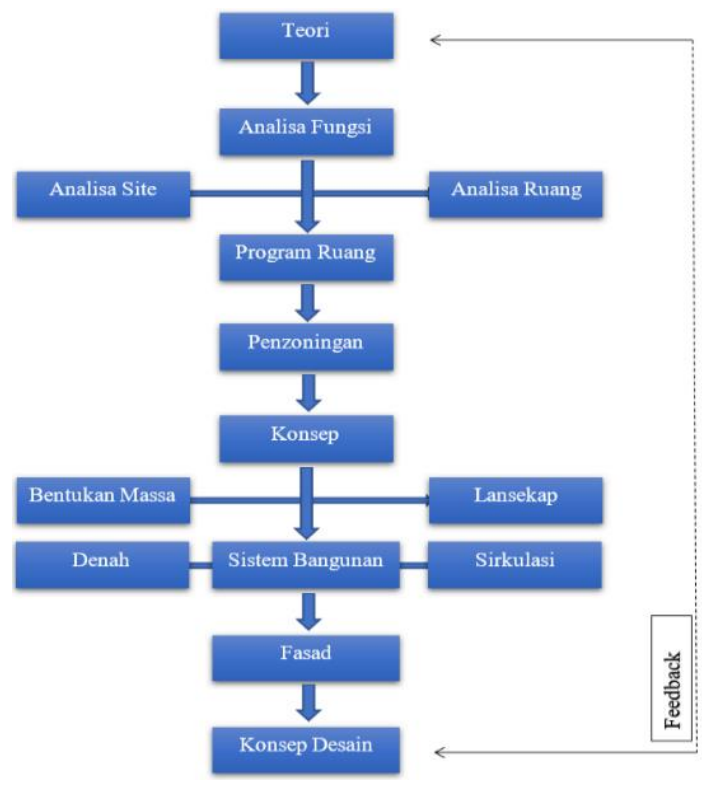

Gambar 1. Alur perancangan

\section{Temuan dan pembahasan}

Coconut center yang merupakan wadah untuk menampung pelbagai kegiatan berkaitan dengan kelapa memiliki fungsi penelitian, kerajinan, rekreasi, edukasi, dan komersil.

Menurut Sahroini (2017) menyatakan bahwa pusat/sentra atau bagian paling penting dari suatu kegiatan atau organisasi dan merupakan tempat 
beraktivitas yang utama atau khusus dan dikonsentrasikan menjadi tempat yang dapat menarik suatu aktivitas untuk berkumpul atau dekonsentrasi untuk fasilitas tertentu (Sahroni 2017). Sedangkan, menurut Dalawir at all (2014), sentra merupakan kawasan industri yang berfungsi sebagai sarana tempat produksi yang didukung dengan fasilitas tempat pameran dan penjualan yang juga sekaligus menjadi tempat wisata (Dalawir, Tilaar, and Poli 2015). Sehingga, coconut center merupakan unit kecil kawasan yang dapat berupa kegiatan kerajinan kelapa, penelitian kelapa, dan komersil. Kegiatan proses produksi merupakan area yang khusus untuk komoditi kelapa yang ditunjang oleh sarana untuk berkembangnya produk dan jasa. Di area sentra tersebut terdapat kesatuan fungsional secara fisik, lahan, geografis, infrastruktur, kelembagaan dan sumberdaya manusia, yang berpotensi mempunyai nilai jual dan daya saing yang tinggi.

Prinsip-prinsip arsitektur biomimetika

Menurut Suryadi (2018) terdapat 3 (tiga) prinsip pada arsitektur biomimetika yaitu (Suryadi 2018): (1) Inspirasi dari bentuk alam (Inspiration from natural forms), yakni meniru bentukan pada alam sekitar, lalu diadopsi kebentuk rancangan bangunan; (2) Inspirasi dari sistem alam (Inspiration from natural systems), yakni inspirasi dari biomimimetika dapat diambil melalui proses hidupnya makhluk hidup, model, teknologi ataupun strukturnya, contoh, sistem fotovoltaik, yang meniru energi pada daun. Menghasilkan sel surya lebih fleksibel dan hemat biaya; (3) Inspirasi dari proses alam (Inspiration from natural process) dapat diambil dari bentuk alami, sistem alam dan proses alami, misalnya pada bangunan The Esplanade Theater, pada display fasade bangunan yang rumit mempengaruhi tampilan dan fungsi interior, bangunan tersebut terinspirasi oleh kulit durian yang berlapis-lapis dengan ketebalan kulit duri yang tertutup.

\section{Lokasi perancangan}

Lokasi tapak berada di Jalan Soebrantas, Indragiri Hilir, Tembilahan (Lihat gambar 2) dengan data fisik sebagai berikut:

Luas lahan: +/- $35000 \mathrm{~m}^{2}$

KDB: $60 \%-70 \%$

Kontur: Relatif datar

Kondisi eksisting: Lahan kosong

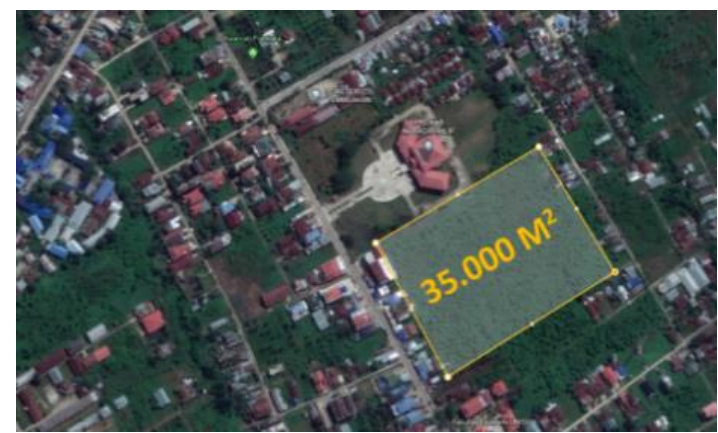

Gambar 2. Lokasi perancangan

Kebutuhan ruang

Analisis kegiatan penggunan dan aktivitas bangunan memengaruhi kebutuhan ruang, maka kebutuhan ruang yang diperlukan untuk bangunan coconut center di Tembilahan agar dapat memaksimalkan fungsi, dijabarkan pada tabel 1 berikut ini.

Tabel 1. Kebutuhan ruang

\begin{tabular}{lll}
\hline Kebutuhan ruang & Jenis kegiatan & $\begin{array}{l}\text { Luasan } \\
\left(\mathbf{m}^{2}\right)\end{array}$ \\
\hline $\begin{array}{l}\text { Komersil, rekreasi, } \\
\text { dan edukasi }\end{array}$ & $\begin{array}{l}\text { Berbelanja, } \\
\text { belajar dan } \\
\text { bersenang-senang }\end{array}$ & $8.423 \mathrm{~m}^{2}$ \\
\hline Pengembangan & $\begin{array}{l}\text { Meneliti, dan } \\
\text { pengembangan }\end{array}$ & $6.746 \mathrm{~m}^{2}$ \\
\hline Produksi & Memproduksi & $18.865 \mathrm{~m}^{2}$ \\
\hline Pengelola & $\begin{array}{l}\text { Mengelola } \\
\text { bangunan }\end{array}$ & $1.366 \mathrm{~m}^{2}$ \\
\hline Servis & Servis & $4.190 \mathrm{~m}^{2}$ \\
\hline & $\begin{array}{l}\text { Luas total }+30 \% \\
\text { sirkulasi }\end{array}$ & $51.467 \mathrm{~m}^{2}$ \\
\hline
\end{tabular}

Sumber: (Neufert 2002)

\section{Penzoningan}

Pada perancangan coconut center di Tembilahan terbagi menjadi beberapa zona yaitu: Zona penelitian, zona produksi, zona rekreasi, zona edukasi, zona komersil, zona servis, zona pengelola, zona perkebunan dan, dan zona parkir (Lihat gambar 3).

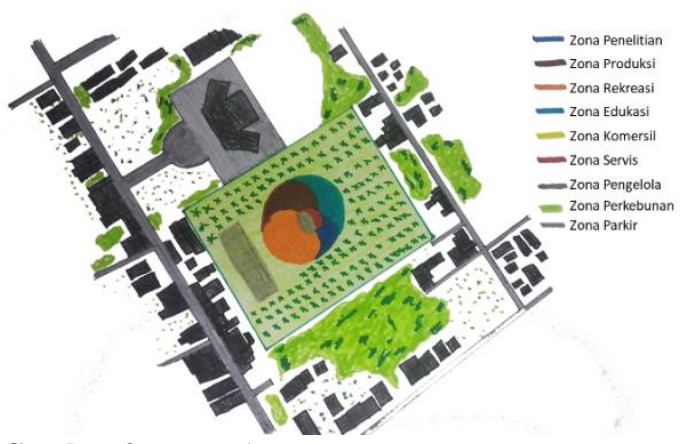

Gambar 3. Penzoningan 


\section{Penerapan tema}

Perancangan coconut center di Tembilahan ini menerapkan tema berdasarkan prinsip-prinsip arsitektur biomimetika yang dijelaskan pada tabel 2 berikut ini.

Tabel 2. Analisis penerapan pendekatan arsitektur biomimetika ke banguna coconut center

\begin{tabular}{|c|c|c|}
\hline No & $\begin{array}{l}\text { Prinsip-prinsip } \\
\text { arsitektur } \\
\text { biomimetika }\end{array}$ & Penerapan \\
\hline 1. & $\begin{array}{l}\text { Inspirasi dari } \\
\text { bentuk alam } \\
\text { (Inspiration from } \\
\text { natural forms) }\end{array}$ & $\begin{array}{l}\text { Setelah melakukan penelitian } \\
\text { tentang kelapa maka, } \\
\text { didapatkan hasil dengan } \\
\text { menggunakan struktur kolom } \\
\text { baja dan beton mengadopsi } \\
\text { batang pohon kelapa yang } \\
\text { berdiri tegap. Bangunan } \\
\text { mengadopsi bentuk batok } \\
\text { kelapa yang dibelah dua, } \\
\text { fasad bangunan mengadopsi } \\
\text { serabut kelapa, semua } \\
\text { terinspirasi dari bentukan } \\
\text { buah kelapa yang merupakan } \\
\text { konsep utama dari bangunan. }\end{array}$ \\
\hline 2. & $\begin{array}{l}\text { Inspirasi dari } \\
\text { sistem alam } \\
\text { (Inspiration from } \\
\text { natural systems) }\end{array}$ & $\begin{array}{l}\text { Setelah melakukan penelitian } \\
\text { tentang sistem pada kelapa } \\
\text { maka, didapatkan inspirasi } \\
\text { dengan menggunakan tiga } \\
\text { lapisan pada struktur atap } \\
\text { yang mengadopsi sistem } \\
\text { pada buah kelapa yang } \\
\text { memiliki tiga lapisan berupa } \\
\text { mesocarp, endocarp, dan } \\
\text { endosperma yang berfungsi } \\
\text { melindungi bagian dalam } \\
\text { kelapa seperti halnya struktur } \\
\text { pada bangunan yang } \\
\text { berfungsi untuk melindungi } \\
\text { bagian dalam bangunan. }\end{array}$ \\
\hline 3. & $\begin{array}{l}\text { Inspirasi dari } \\
\text { proses alam } \\
\text { (Inspiration from } \\
\text { natural process) }\end{array}$ & $\begin{array}{l}\text { Setelah meneliti tentang } \\
\text { proses yang terjadi pada } \\
\text { kelapa didapatkan inspirasi } \\
\text { untuk mengadopsi akar } \\
\text { serabut pada pohon kelapa } \\
\text { yang akan di terapkan pada } \\
\text { pola sirkulasi pada interior } \\
\text { bangunan, akar serabut pada } \\
\text { pohon kelapa yang berfungsi } \\
\text { sebagai masuknya mineral } \\
\text { dan air untuk kelangsungan } \\
\text { hidup pohon sejalan dengan } \\
\text { fungsi sirkulasi pada banguan } \\
\text { yaitu sebagai jalur masuknya } \\
\text { pengunjung dan pengguna } \\
\text { bangunan sebagai sumber } \\
\text { kelangsungan fungsi dari } \\
\text { bangunan. }\end{array}$ \\
\hline
\end{tabular}

Konsep

Bentukan massa bangunan terinspirasi dari buah kelapa yang dibelah menjadi dua dan dihubungkan (Lihat gambar 4). Alasan bentuk bangunan yang mengambil bentuk kelapa dibelah dua adalah untuk keperluan ruang yang banyak dan memisahkan antara fungsi produksi serta fungsi penelitian. Sehingga, tidak mengganggu fungsi satu sama lainnya (Khoshtinat 2015).

Pengambilan bentukan buah kelapa berdasarkan dari tema biomimetik pada tingkat ekosistem, sehingga bangunan mengadopsi proses alami dan siklus lingkungan yang lebih besar. Ekosistem yang dimaksudkan yakni bergantung pada sinar matahari, mengoptimalkan sistem dari pada aspek bentuknya, selaras dan bergantung pada kondisi sekitar, serta menciptakan kondisi yang menguntungkan untuk hidup berkelanjutan.

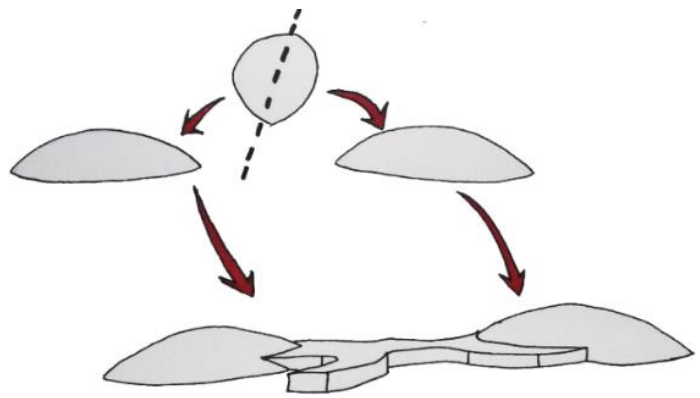

Gambar 2. Konsep bentukan

Konsep fasad atau tampilan

Fasad coconut center memiliki bentuk abstrak yang meniru serabut kelapa, tidak beraturan, dan juga agar radiasi matahari yang masuk ke bangunan tidak berlebihan. Fasad juga membuat interior bangunan menjadi lebih bagus karena bayangan terbentuk bentukan abstrak yang menambah estetika (Lihat gambar 5).

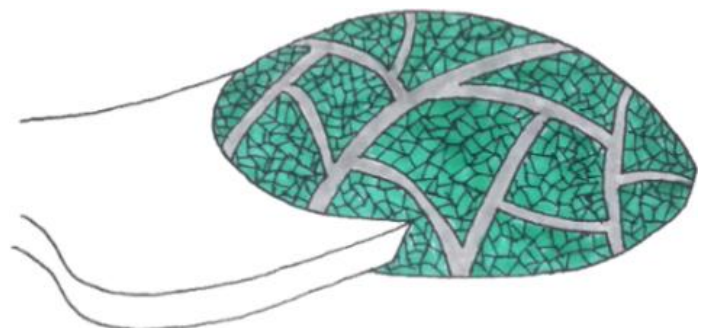

Gambar 3. Konsep fasad pada bangunan

Konsep interior

Interior bangunan coconut center memanfaatkan pencahayaan alami, mengurangi atau meminimalisir dampak negatif dari bangunan, lebih hemat energi, dan terdapat bukaan-bukaan yang dapat menjadi sumber penghawaan alami bagi bangunan (Widodo 2019; Subroto 2019). 
Penggunaan material pada interior bangunan juga banyak menggunakan material yang ramah lingkungan dan alami, serta memanfaatkan hasil produksi dari bangunan coconut center seperti perabotan dan fasad pada interior (Christina, de Yong, and Basuki 2019; Pradono 2019; De Chiara 1991) (Lihat gambar 6).

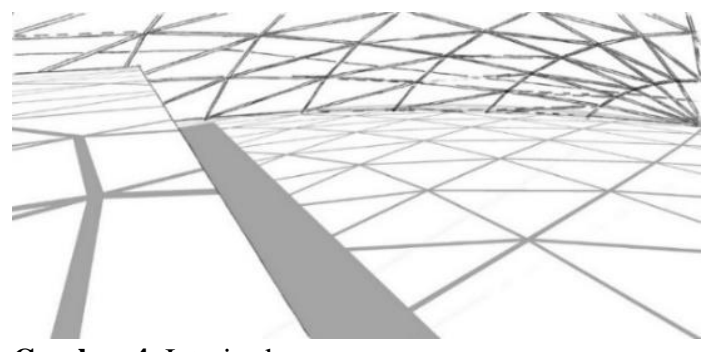

Gambar 4. Interior bangunan

Konsep vegetasi

Lansekap pada bangunan coconut center menggunakan eksisting tanaman pohon kelapa dan akan dimanfaatkan menjadi sumber bahan bagi produksi pada bangunan, selain untuk membuat site lebih hijau dan sejuk, dapat juga membuat suasana menjadi tenang (Lihat gambar 7).

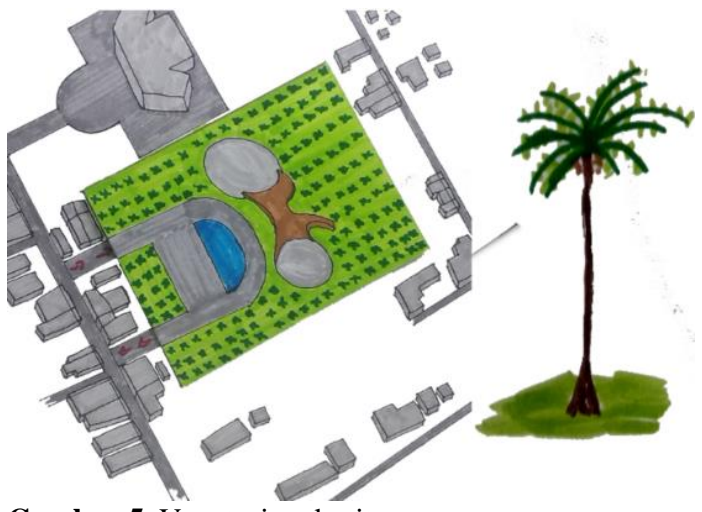

Gambar 5. Vegetasi pada site

Konsep sirkulasi dan parkir

Pola sirkulasi satu arah, hanya dapat dicapai melalui Jalan Soebrantas. Sirkulasi kendaraan dirancang melewati bangunan dan aman ketika dalam situasi darurat.

Pola sirkulasi sederhana dan memudahkan para pengguna bangunan. Lebar jalan 6 meter, sehingga aman pada saat keadaan darurat (Lihat gambar 8).

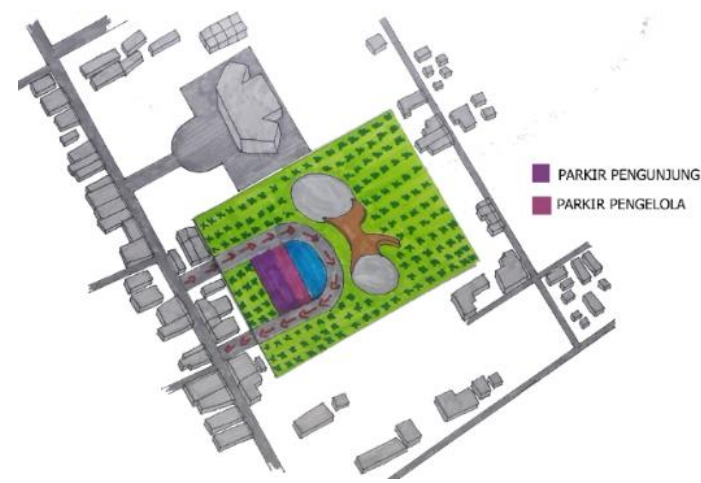

Gambar 6. Sirkulasi dan zonasi parkir

\section{Kesimpulan}

Kesimpulan coconut center dengan pendekatan biomimetika di Tembilahan adalah sebagai berikut: (1) Penyusunan kebutuhan ruang akan di rancang untuk dapat mewadahi kebutuhan dan fungsi ruang sehingga, dapat mengefektifkan penggunaan bangunan untuk kegiatan yang akan di wadahi di coconut center; (2) Menerapkan tema rancangan yaitu Biomimetika berdasarkan prinsip-prinsip yang terdapat pada tema rancangan dengan menerapkan keseluruhan prinsip biomimetika pada rancangan bangunan; (3) Konsep pohon kelapa merupakan tanaman serbaguna yang memiliki nilai ekonomi tinggi. Serupa dengan tema biomimetika pada tingkat ekosistem, konsep pohon kelapa akan diterapkan pada keseluruhan rancangan bangunan.

Adapun beberapa saran yang diberikan oleh penulis terhadap perancangan coconut center dengan pendekatan biomimetika di Tembilahan adalah sebagai berikut: (1) Mempertimbangkan pemilihan lokasi perancangan sesuai dengan kebutuhan bangunan; (2) Dalam perancangan coconut center ini diharapkan memperhatikan pelbagai fungsi pada bangunan yang bersifat atraktif yang akan diwadahi oleh perancangan ini; (3) Dalam perancangan coconut center ini perlu mempertimbangkan tema sehingga mampu memberikan ketertarikan terhadap bangunan itu sendiri. 


\section{Referensi}

Agustin, Rezy Kurnia, Yohannes Firzal, and Pedia Aldy. 2018. 'Penerapan Prinsip Form Follow Function Pada Pusat Penelitian Dan Budidaya Kelapa Hibrida Di Indragiri Hilir'. JOM FT Universitas Riau 5 (2). https://jom.unri.ac.id/index.php/JOMFTEKN IK/article/view/21521/20822.

Baumeister, Dayna. 2012. Biomimicry Resource Handbook. Biomimicry. New York: Missoula MT, USA.

Bhikuning, Annisa. 2013. 'Analisa Performa Mesin Dengan Biodiesel Terbuat Dari Virgin Coconut Oil Pada Mesin Diesel'. Jurnal Energi Dan Manufaktur 6 (2): 123-28. https://ojs.unud.ac.id/index.php/jem/article/vi ew/10003/7440.

Chiara, Joseph De. 1991. Time-Saver Standards for Interior Design and Space Planning. New York: Mc Grawhill Company.

Christina, Novia, Sherly de Yong, and Lucky Basuki. 2019. 'Perancangan Interior Sentra Galeri Dan Workshop Kerajinan Kayu Di Blora, Jawa Tengah'. Intra 7 (2). http://publication.petra.ac.id/index.php/desai n-interior/article/view/8955.

Dalawir, Alexander, Sonny Tilaar, and Hanny Poli. 2015. 'Sentral Industri Kain Koffo Di Manganitu (Arsitektur Organik)'. Jurnal Arsitektur DASENG 4 (1): 46-55.

Eman, Arviro, and Octavianus H. A. Rogi. 2013. 'Implementasi Konsep Arsitektur Biomimetik Pada Desain Gelanggang Olahraga Di Minahasa Selatan'. Jurnal Arsitektur DASENG UNSRAT 2 (1): 31-41. https://ejournal.unsrat.ac.id/index.php/daseng /article/view/3457/pdf.

Fitriana, Aisyah Nurul. 2014. 'Pengembangan Industri Kreatif Di Kota Batu (Studi Tentang Industri Kreatif Sektor Kerajinan Di Kota Batu)'. JAP (Jurnal Administrasi Publik) 2 (2).

Hadi, Syaiful. 2017. 'Model Pengembangan Industri Kelapa Di Provinsi Riau'. In Seminar Nasional Perencanaan Pembangunan Pembangunan Inklusif Desa Kota, 183-90. Padang, Sumatera Barat: Pascasarjana Universitas Andalas.

Indahyani, Titi. 2011. 'Pemanfaatan Limbah Sabut Kelapa Pada Perencanaan Interior Dan
Furniture Yang Berdampak Pada Pemberdayaan Masyarakat Miskin'. Humaniora 2 (1): 15. https://doi.org/10.21512/humaniora.v2i1.294 1.

Kementerian Perdagangan Republik Indonesia. 2017. 'Optimalisasi Bahan Baku Kelapa'. Warta Ekspor, September 2017.

Khoshtinat, Shiva. 2015. Algorithms In Nature \& Architecture (Biomimetic Architecture). Firenze: Univertita Degli Studi Di Firenze.

Neufert, Ernest. 2002. Data Arsitek. 33rd ed. Jakarta: Erlangga.

Pradono, Budi. 2019. 'The Interiority of Proximity Between Nature and Architecture in Contemporary and Tropically Context with Cases Studies'. ARTEKS: Jurnal Teknik Arsitektur 3 (2): $129-44$. https://doi.org/10.30822/arteks.v3i2.63.

Sahroni, Latifah. 2017. 'Pusat Penelitian Dan Pengembangan Kelapa Sawit Di Rokan Hulu Dengan Pendekatan Arsitektur Hijau'. Universitas Riau.

Schouten, Frendy P. Y., Sangkertadi, and Frits O. P. Siregar. 2015. 'Biodome Di Manado (Arsitektur Biomimetika)'. Jurnal Arsitektur DASENG UNSRAT 4 (2): 109-18. https://ejournal.unsrat.ac.id/index.php/daseng /article/view/8890/pdf.

Subroto, T. Yoyok Wahyu. 2019. 'Koeksistensi Alam Dan Budaya Dalam Arsitektur'. ARTEKS : Jurnal Teknik Arsitektur 3 (2): vviii. https://doi.org/10.30822/artk.v3i2.244.

Suryadi, Machfudz Ardi. 2018. 'Perancangan Pusat Kuliner Berbahan Unggas Dengan Pendekatan Biomimicry Architecture Di Kabupaten Malang'. Universitas Islam Negeri Maulana Malik Ibrahim. http://etheses.uinmalang.ac.id/12366/.

Vaulina, Sisca. 2019. 'Kajian Komparasi Produksi Dan Pendapatan Usahatani Kelapa Dalam (Cocos Nucifera Linn) Berdasarkan Tipologi Lahan Di Kabupaten Indragiri Hilir'. Jurnal Agribisnis 21 (1): 84-98. https://doi.org/10.31849/agr.v21i1.2733.

Widodo, Johannes. 2019. 'Human, Nature, And Architecture'. ARTEKS: Jurnal Teknik $\begin{array}{llll}\text { Arsitektur } & 3 & \text { (2): } 145-48 .\end{array}$ https://doi.org/10.30822/arteks.v3i2.65. 